\begin{tabular}{|c|c|c|c|}
\hline \multirow{3}{*}{$\begin{array}{r}\text { Case Reports in } \\
\text { Gastroenterology }\end{array}$} & Case Rep Gastroenterol 2016; & & \multirow[b]{2}{*}{$\begin{array}{l}\text { Karger } \\
\text { Open ăccess }\end{array}$} \\
\hline & $\begin{array}{l}\text { DOI: } 10.1159 / 000452736 \\
\text { Publisned ontune: November 25, } 2016\end{array}$ & $\begin{array}{l}\text { (c) } 2016 \text { The Author(s) } \\
\text { Published by S. Karger AG, Basel } \\
\text { www.karger.com/crg }\end{array}$ & \\
\hline & $\begin{array}{l}\text { This article is licensed under the } \mathrm{Cr} \\
\text { International License (CC BY-NC) (ht } \\
\text { Usage and distribution for commercial }\end{array}$ & $\begin{array}{l}\text { nons Attribution-NonCommercial } 4 . C \\
\text { ger.com/Services/OpenAccessLicense) } \\
\text { uires written permission. }\end{array}$ & \\
\hline
\end{tabular}

\title{
Sphincter of Oddi Dysfunction: A Perplexing Presentation
}

\author{
Sana Ahmad Din Iman Naimi Mirza Beg \\ Division of Pediatric Gastroenterology, Hepatology and Nutrition, SUNY Upstate \\ Medical University, Golisano Children's Hospital, Syracuse, NY, USA
}

\section{Keywords}

Sphincter of Oddi - Endoscopic retrograde cholangiopancreatography · Cholecystectomy · Abdominal pain $\cdot$ Pediatrics

\begin{abstract}
Sphincter of Oddi dysfunction is caused by stenosis or dyskinesia of the sphincter of Oddi, leading to blockage of bile drainage from the common bile duct. We present the case of a 16-year-old female with chronic abdominal pain who underwent laparoscopic cholecystectomy for cholelithiasis but continued to experience abdominal pain, nausea, and vomiting along with persistently elevated ALT and AST levels. Postoperative abdominal ultrasound was nondiagnostic. Esophagogastroduodenoscopy showed mild reflux esophagitis and mild chronic Helicobacter pylori-negative gastritis. Omeprazole was started, but it did not decrease the frequency and severity of the abdominal symptoms. Magnetic resonance cholangiopancreatography did not reveal any pathology. Endoscopic retrograde cholangiopancreatography with manometry confirmed an elevated biliary sphincter pressure. Biliary sphincterotomy was performed, and the symptoms improved.

(C) 2016 The Author(s) Published by S. Karger AG, Basel
\end{abstract}

\section{Introduction}

Sphincter of Oddi dysfunction (SOD) results from a mechanical or functional obstruction of the sphincter of Oddi (SO) that leads to the presentation of a clinical syndrome [1, 2]. SOD 


\section{Case Reports in Gastroenterology}

Case Rep Gastroenterol 2016;10:714-719 DOI: $10.1159 / 000452736$

(c) 2016 The Author(s). Published by S. Karger AG, Basel www.karger.com/crg

Din et al.: Sphincter of Oddi Dysfunction: A Perplexing Presentation

is synonymous with papillary stenosis, biliary spasm, sclerosing papillitis, and postcholecystectomy syndrome. SOD can be caused by SO stenosis or dyskinesia [3, 4]. Patients with the clinical syndrome of SOD may present with abdominal pain, elevation of pancreatic or liver enzymes, common bile duct dilation, or episodes of recurrent pancreatitis. Episodes of idiopathic recurrent pancreatitis are known as 2 or more attacks of acute pancreatitis of uncertain etiology with complete resolution of the pancreatitis in between the episodes [3, 4].

SO stenosis is a narrowing of the SO due to various mechanisms and is an anatomic abnormality. The known causes of SO stenosis are the results of inflammation that leads to scarring of the SO, such as pancreatitis, gallstones passing across the biliary tree to the SO, trauma, and infections. Another cause of SOD is SO dyskinesia, which is a functional abnormality leading to periodic obstruction. The exact etiology of SO dyskinesia is unknown, but it is understood to be caused by spasms and relaxation of the SO [5].

Cholecystectomy is done prophylactically to prevent recurrent biliary colic attacks due to gallstones. Some serious complications include bleeding, bile duct injury, bile leak, and bowel injury; however, the most common complaint is intermittent abdominal pain [6]. Postcholecystectomy syndrome is an adverse outcome that can occur after cholecystectomy [7]. The syndrome presents as persistent abdominal pain and dyspepsia [8, 9]. It is divided into 2 phases: early postcholecystectomy syndrome occurs during the postoperative period, and late postcholecystectomy syndrome occurs months after cholecystectomy. Postcholecystectomy syndrome can have biliary and extrabiliary etiologies. Common biliary causes are biliary injury, a retained cystic duct, stones in the common bile duct, bile duct strictures, an inflamed cystic duct, and biliary dyskinesia. Common extrabiliary causes are irritable bowel syndrome, pancreatitis, peptic ulcer disease, hepatitis, mesenteric ischemia, intercostal neuritis, diverticulitis, wound neuroma, and psychosomatic disorders [9].

The SO is a circular muscle at the distal aspect of the biliary tree that controls the flow of bile and pancreatic juices into the duodenum. It surrounds the merging of 2 ducts: the common bile duct and the pancreatic duct. The motility of the SO during the fasting state is controlled by the migrating motor complex (MMC) [10]. The MMC is composed of 4 phases that coordinate the release of bile into the duodenum. The motility of the SO during the fed state depends on the type and amount of food and is influenced by cholecystokinin.

Biliary SOD should be suspected in patients who present with pain in the right upper quadrant (RUQ) or epigastrium lasting from $30 \mathrm{~min}$ to hours without an obvious cause. Patients with SOD may present with elevation of ALT, AST, and alkaline phosphatase. The laboratory abnormalities may revert to normal in between attacks. On ultrasound (US), the common bile duct may be dilated. Pancreatic SOD presents with recurrent pancreatitis. Patients will have elevated amylase, ALT, and AST, as well as possible dilation of the pancreatic duct [11].

\section{Case Presentation}

A 16-year-old female was referred to our gastroenterology clinic for persistent episodic RUQ abdominal pain. The patient's workup revealed hypertransaminasemia (AST level 618 U/L; ALT level $360 \mathrm{U} / \mathrm{L}$ ), and RUQ abdominal US showed cholelithiasis. Laparoscopic cholecystectomy was performed without any complications; however, the patient's abdominal symptoms did not improve. She complained of brief episodes (20-30 min) of abdominal pain that radiated to her back, even though she had normal physical examination. Her complete blood count with differentials, erythrocyte sedimentation rate, basic metabolic profile, amy- 


\section{Case Reports in \\ Gastroenterology}

Case Rep Gastroenterol 2016;10:714-719

DOI: $10.1159 / 000452736$

(c) 2016 The Author(s). Published by S. Karger AG, Basel www.karger.com/crg

Din et al.: Sphincter of Oddi Dysfunction: A Perplexing Presentation

lase, lipase, creatinine phosphokinase, Epstein-Barr virus panel, $\alpha_{1}$-antitrypsin levels, total protein, alkaline phosphatase, and radiologic screen were normal. She was negative for celiac serology, antinuclear antibody, and anti-smooth muscle antibody. Endoscopy with biopsy was normal. The patient's repeat US, CT scan, and magnetic resonance cholangiopancreatography were normal. The only laboratory test abnormality were elevated liver function test results (Fig. 1) and an AST:ALT ratio of 2:1, but she denied using alcohol. SOD became our differential diagnosis after ruling out infectious, autoimmune, liver, and pancreatic abnormalities. Endoscopic retrograde cholangiopancreatography (ERCP) with manometry was performed, which revealed an elevated biliary sphincter phasic pressure of $86 \mathrm{~mm} \mathrm{Hg} 4 \mathrm{~mm}$ from the papillary opening, which confirmed SOD (Fig. 2). Endoscopic sphincterotomy and papillotomy were performed. After surgery, the patient did not experience any abdominal pain and continued to do well.

\section{Discussion}

The biliary tract is responsible for the transport, storage, and regulation of hepatic bile. Bile moves from the intrahepatic and extrahepatic ducts towards the duodenum to aid in the digestion and absorption of fat [12]. The resistance of the SO increases during the interdigestive phase, due to phasic contractions resulting in an increase in ductal pressure [12]. This results in relaxation of the gallbladder due to the choledochocystic duct reflex. The pressure gradient between the common bile duct and the gallbladder allows the bile to flow from the cystic duct to the gallbladder. The bile is circulated continuously during the digestive and interdigestive phases via propulsive and nonpropulsive contractions in the gallbladder and the cystic duct [12].

The MMC originates in the upper gastrointestinal tract during the fasting or interdigestive phase [10]. The interdigestive phase is responsible for the storage of bile [12]. The MMC is made up of 4 phases. Phase I is the quiescent period, in phase II there are intermittent contractions, in phase III there are brief high-amplitude contractions, and phase IV is responsible for transition into the next phase I [10]. The propulsive contractions in the gallbladder and the propulsive phase III of the MMC result in partial emptying of the gallbladder [12]. The digestive phase is responsible for moving the bile from the gallbladder to the duodenum via gallbladder contractions and relaxation of the SO. The SO is relaxed by a neurohormonal mechanism. Additionally, the SO is engaged in the regulation of pancreatic secretions into the duodenum. Any disorder in this pathway may cause intermittent abdominal pain, transient elevation of liver function enzymes, transient elevation of pancreatic enzymes, or pancreatitis [12].

SOD is defined as a clinical syndrome that can cause abdominal pain, elevation of pancreatic or liver enzymes, common bile duct dilation, or episodes of recurrent pancreatitis caused by mechanical or functional abnormality of the biliary sphincter, the pancreatic sphincter, or both [11]. The SO is a muscle valve; therefore, mechanical SOD results when there is an abnormality in the muscle valve preventing the bile and pancreatic enzymes from proceeding into the duodenum [13]. Functional SOD is a motor problem in the biliary or pancreatic SO [12]. Biliary SOD usually presents as transient biliary obstruction, whereas pancreatic SOD presents as recurrent pancreatitis with elevated pancreatic enzymes $[12,7]$. Patients with functional SOD present with recurrent RUQ pain similar to colics without biliary stones, as seen in our patient. It is crucial to rule out liver and pancreatic abnormalities 
Din et al.: Sphincter of Oddi Dysfunction: A Perplexing Presentation

before any invasive procedures, such as endoscopic and surgical procedures for suspected functional SOD, as done in our patient [12].

The prevalence of SOD is $1.5 \%$ in adult patients who undergo cholecystectomy. SOD is diagnosed in adults but is not commonly considered in differential diagnoses in children. SOD is more common in females than in males [12]. The diagnostic workup sequence for both biliary and pancreatic SOD starts with a liver biochemistry and pancreatic enzymes followed by US, magnetic resonance cholangiopancreatography, and ERCP with SO manometry, as done in our patient [12]. Due to the limited use of ERCP with SOD in children, a normal pressure has not been established for this population. Therefore, pressures above 40 $\mathrm{mm} \mathrm{Hg} \mathrm{-} \mathrm{which} \mathrm{is} \mathrm{the} \mathrm{maximal} \mathrm{basal} \mathrm{pressure} \mathrm{in} \mathrm{SOD} \mathrm{established} \mathrm{for} \mathrm{adults} \mathrm{-} \mathrm{are} \mathrm{used} \mathrm{for}$ diagnostic purposes in pancreatic and biliary SOD [12]. A known complication of ERCP is pancreatitis, and a few cases have been reported among children with SOD after biliary sphincterotomy. Prophylactic pancreatic stenting can be performed to prevent post-ERCP pancreatitis, since it decreases the incidence of pancreatitis; however, more data are needed to evaluate its long-term significance [14].

Treatment for adults with SOD of the biliary type is endoscopic sphincterotomy, as was done in our patient. Nifedipine has been reported to be beneficial; however, more data are needed for a long-term evaluation [12]. Treatment for adults with pancreatic SOD is total division of the SO. This treatment permits the flow of bile and of pancreatic enzymes from both the biliary and the pancreatic sphincters into the duodenum [12]. A prospective study suggested that in children endotherapy is effective, but more data are needed to support this treatment [14].

\section{Conclusion}

Even though SOD is not a common diagnosis in children, pediatricians and pediatric gastroenterologists should maintain a high index of suspicion when patient presents with recurrent abdominal pain after cholecystectomy with elevated liver enzymes. This will ensure timely diagnosis and treatment, as well as avoidance of unnecessary workups and prolongation of symptoms, which can negatively affect the quality of life. Data on the safety and longterm efficacy of endoscopic sphincterotomy in children with SOD are scarce, and prospective randomized trials are required for further evaluation [14].

\section{Acknowledgement}

We want to thank Wahhaj Bakht from the Department of Ecology and Evolutionary Biology, University of Connecticut, Storrs, CT, USA, for his assistance with editing and with comments that greatly improved the manuscript.

\section{Statement of Ethics}

The authors have no ethical conflicts to disclose. 


\section{Case Reports in \\ Gastroenterology}

(c) 2016 The Author(s). Published by S. Karger AG, Basel www.karger.com/crg

Din et al.: Sphincter of Oddi Dysfunction: A Perplexing Presentation

\section{Disclosure Statement}

There is no conflict of interest regarding the publication of this manuscript.

\section{References}

-1 Sostre S, Kalloo AN, Spiegler EJ, Camargo EE, Wagner HN Jr: A noninvasive test of sphincter of Oddi dysfunction in postcholecystectomy patients: the scintigraphic score. J Nucl Med 1992;33:1216-1222.

2 Tzovaras G, Rowlands BJ: Diagnosis and treatment of sphincter of Oddi dysfunction. Br J Surg 1998;85:588-595.

3 Chuttani R, Carr-Locke DL: Pathophysiology of the sphincter of Oddi. Surg Clin North Am 1993;73:1311-1322.

4 Toouli J: Sphincter of Oddi. Gastroenterologist 1996;4:44-53.

5 Catalano MF, Thosani NC: Clinical manifestations and diagnosis of sphincter of Oddi dysfunction. 2016. http://www.uptodate.com/contents/clinical-manifestations-and-diagnosis-of-sphincter-of-oddidysfunction.

-6 Vijayakumar V, Briscoe EG, Pehlivanov ND: Postcholecystectomy sphincter of Oddi dyskinesia - a diagnostic dilemma - role of noninvasive nuclear and invasive manometric and endoscopic aspects. Surg Laparosc Endosc Percutan Tech 2007;17:10-13.

7 Soper NJ, Malladi P: Laparoscopic cholecystectomy. 2016. http://www.uptodate.com/contents/laparoscopic-cholecystectomy?source=search_result\&search= 7\%09Soper+N\%2C+Malladi+P\%3A+Laparoscopic+cholecystectomy\&selectedTitle=2\%7E64.

-8 Girometti R, Brondani G, Cereser L, et al: Post-cholecystectomy syndrome: spectrum of biliary findings at magnetic resonance cholangiopancreatography. Br J Radiol 2010;83:351-361.

-9 Lamberts MP, Den Oudsten BL, Gerritsen JJ, et al: Prospective multicentre cohort study of patientreported outcomes after cholecystectomy for uncomplicated symptomatic cholecystolithiasis. Br J Surg 2015;102:1402-1409.

10 Tanaka M: Function and dysfunction of the sphincter of Oddi. Dig Surg 2010;27:94-99.

11 Mudombi WF, Mahomed AD: Sphincter of Oddi dysfunction review. South African Gastroenterol Rev 2015;13:7-11.

12 Behar J, Corazziari E, Guelrud M, Hogan W, Sherman S, Toouli J: Functional gallbladder and sphincter of Oddi disorders. Gastroenterology 2006;130:1498-1509.

13 Jamidar P, Aslanian H, Farrell J, Ruby J: SOD (Sphincter of Oddi Dysfunction). Yale Center of Advanced Endoscopy and Pancreatic Disease. 2016.

14 Varadarajulu S, Wilcox CM: Endoscopic management of sphincter of Oddi dysfunction in children. J Pediatr Gastroenterol Nutr 2006;2:526-530. 
Din et al.: Sphincter of Oddi Dysfunction: A Perplexing Presentation

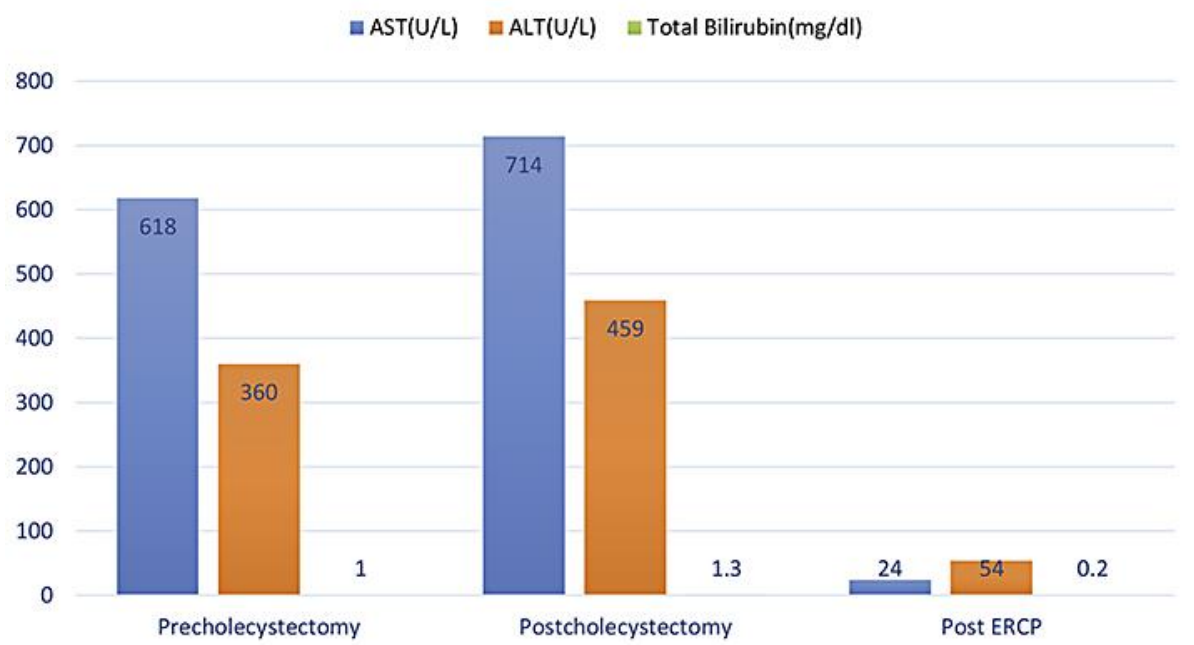

Fig. 1. The graph highlights the AST, ALT, and total bilirubin levels prior to cholecystectomy, after cholecystectomy, and after ERCP. It is to be noted that the patient had an AST/ALT ratio of 2:1 with normal total bilirubin levels. The patient had hypertransaminasemia after cholecystectomy and improved after ERCP.

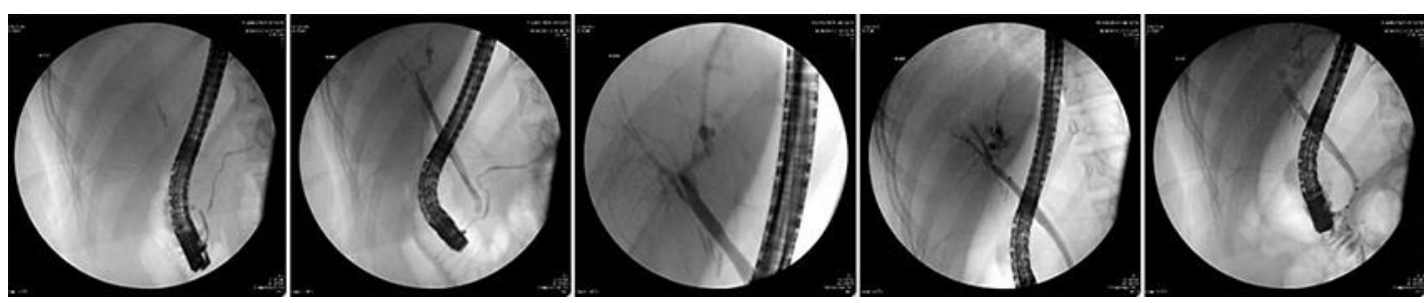

Fig. 2. ERCP was performed for abdominal pain of suspected biliary cause and for abnormal liver enzymes. The images demonstrate an endoscope reaching the duodenum. There is contrast material filling the pancreatic duct, common bile duct, intrahepatic duct, and extrahepatic duct. The distal common bile duct near the ampulla is not opacified. The biliary manometry established that the biliary phasic pressure was elevated to $86 \mathrm{~mm} \mathrm{Hg}$. 